\title{
The Impact of Casino Gambling on Charitable Contributions: The Willingness to Contribute to a Local Public Television Station
}

\author{
R. Keith Schwer and Rennae Daneshvary*
}

\begin{abstract}
This study examines factors that influence Las Vegas residents' willingness to pay (WTP) to maintain public television programming locally. Though previous research has investigated WTP for public television, this study is unique in that it examines the impact of casino gambling on giving. A mail survey with two follow-ups yielded 1,054 surveys- -880 surveys provided complete information on the variables used in two analyses, 557 in a third. Statistically significant effects were found in models estimated with Tobit models; however, we failed to find a significant reduction in contributions to public television with higher levels of gambling behavior.
\end{abstract}

\section{INTRODUCTION}

Interest in the social and economic impacts of gaming by social scientists has flourished with the proliferation of casinos beyond one state (Nevada) in the last 20 years. Examples include the effects of casino gambling on property values (Giannini et al. 1997), community revenue losses (Aasved and Laundergan 1993; Aasved, Schaefer, and Merila 1995; Gazel, Rickman, and Thompson 1995), crime (Buck et al.1991; Friedman, Hakim, and Weinblatt 1989), and families (Gaudia 1987) to name but a few of the concerns attracting attention and study. Lacking, however, is a study of the effect of casino gambling on charitable contributions.

Borg, Mason, and Shapiro (1991), examining the economic consequences of state lotteries on consumer spending, found differences in household expenditures between households participating in the lottery (lottery households) and those not participating (nonlottery households) before and after the adoption of lotteries. Analyzing a random consumer-expenditure sample of Florida and Georgia residents between 1987 and 1989, they found that charitable giving, one of the twenty expenditure categories studied, was the only category in which expenditures declined. Gazel, Rickman, and Thompson (1995) in their study of the economic impacts of casino gambling in Wisconsin reported a shift in residents' expenditure patterns, income, and employment away from other sectors to casinos as a result of the adoption of legalized gambling. The decline in expenditures was especially apparent for the grocery and the retail trade sectors. Madden (1992), estimating the economic impact of gambling in Deadwood, South Dakota, found that, while gambling expenditures increased, 11 of 19 sectors saw decreases in taxable sales from 1989 to 1991 . These sectors included gross wholesale trade, general merchandise, food stores, automotive, apparel, furniture, personal services,

"Director of the Center for Business and Economic Research and professor of Economics, University of Nevada, Las Vegas and Assistant Director, Center for Business and Economic Research, University of Nevada, Las Vegas. 
business services, auto repair, health services, and accounting services. Aasved, Schaefer, and Merila (1995) calculated that "per capita gambling expenditures in Minnesota in 1990 was $\$ 558$ compared to $\$ 40$ per capita average for movies and videotape rentals" (p. 138). Thus, the introduction of gaming is likely to shift consumer spending and saving patterns, including contributions to charities.

As such, one would reasonably expect public television, a form of recreation, to lose viewership among households actively participating in legalized casino gambling. This premise is supported by Kingma and McClelland's study (1995), which demonstrated that household contributions to public radio were positively affected by the amount used. Similarly, Schwer and Daneshvary (1995) concluded that Public Broadcasting System (PBS) viewing time of greater than 20 hours per week had a positive effect on the amount people would willingly contribute to PBS.

As suggested, evidence on household consumption patterns leads one to believe that those who gamble for recreation (the available evidence, albeit less definitive than one might desire, nonetheless suggests this to be the primary reason for the preponderance of gamblers) reduce their charitable contributions, perhaps including contributions to public television. It is quite likely that gambling comes from household discretionary budgets; therefore, other objects of discretionary spending, including charitable giving, should be expected to be affected by the volume of a person's gambling. But whether voluntary contributions to supplement government subsidies of PBS significantly decline with increased gambling activity remains an unanswered question. To evaluate the impact of gambling on PBS contributions, this study identifies factors that influence the willingness of Las Vegans, residents of a community long identified with casino gaming and not subject to the possible transitory effects of recent casino gambling legalization, to contribute to public television. In particular, it will determine if willingness to contribute to maintain PBS programming locally is significantly affected by residents' involvement in gaming, measured by the amount of money budgeted for gambling, the frequency of casino visitation, and fondness for gambling. The presence of significant inverse relationships between these measures of gambling and contributions to PBS would offer credence to gambling activity being a substitute for charity contributions.

\section{REVIEW OF LITERATURE}

Though the Corporation for Public Broadcasting, which comprises 351 TV and 600-plus public radio stations, survived the anticipated major budget cuts argued for by Republicans during the 104th Congress, the debate over funding continues. One critic's explanation for PBS' survival is that "affection for Big Bird ran deeper than a desire to kill liberal propaganda" (Boot 1995, p. 18). Critics further claim that PBS is inefficient when it overpays for its popular shows and pays large salaries to its stars. Furthermore, PBS programming has become indistinguishable from other stations, such as $A \& E$ and the Discovery Channel. 
Proponents, however, respond by pointing to PBS' lack of commercials and its quality programming. As one supporter stated in response to a critic's charge of the indistinguishability of PBS and commercial television, "I think your readers should seriously question the credibility of anyone who can't tell the difference between 'Masterpiece Theater' and 'Married With Children'" (Ruple 1995, p. 23).

PBS survives on funds ( $\$ 275$ million in 1996) received from the government and contributions from viewers. The value that viewers place on public television is reflected by the amount they contribute. Limited work has been done on contributions to public television. Goetze, Glover, and Biswas (1993) used data from 137 public television stations to determine the change in private contributions to public television as the size of the viewing audience and income changed. They found that as group size increased, aggregate contributions increased but individual contributions decreased. Furthermore, total contributions increased at an increasing rate to income.

Using the contingent valuation method (CVM) to determine willingness to pay (WTP), Bohm (1972) investigated contributions in Sweden. Schwer and Daneshvary (1995) studied WTP for public television in southern Nevada. The latter study, using ordinary least squares, restricted least squares, and Tobit censored regression methods, revealed that preference for cable television, amount of viewing time, and a college education (in at least one model) were significant effects on WTP for public television. Nonetheless, these two studies, though insightful on the determinants of WTP contributions, leave unanswered the effect of gambling on contributions to PBS.

In most CVM studies, "the researcher formulates a hypothetical market situation in which a good is made available to respondents and, in one or a series of questions, attempts to elicit the maximum price respondents would be WTP for the good" (Schwer and Daneshvary 1995, p. 97). Extensive survey research has been done to measure WTP for a wide range of goods, such as air pollution (Loehman, Boldt, and Chaikin 1981; Brookshire et al. 1982), water quality (Desvousges, Smith, and McGivney 1983), and soil and forest conservation (Sinden 1988). Likewise, extensive research has been done to test for inherent biases in the various types of CVM used. Thus, a growing body of work addresses the legitimacy of CVM in assessing WTP.

This study uses the open-ended single-question WTP method. This method, previously questioned because the lack of guidance to survey respondents has resulted in some unrealistic responses, has made a comeback (Vining et al. 1994). Other methods such as the closed-ended iterative bidding methods and the dichotomous-choice method proved sensitive to the starting price. The openended method is not. Ideally, an open-ended method used with another method might eliminate or reduce the biases of both methods (Vining et al. 1994). However, public television is a familiar good to the majority of southern Nevadans; therefore, the problem of unrealistic responses seems unlikely in this case. Thus, the single-question open-ended method should be the best for assessing valuation of public television. 


\section{A MODEL FOR PUBLIC TELEVISION}

Using the individual choice-theoretic framework, one can specify an inverse Hicksian demand for PBS (Schwer and Daneshvary 1995). The WTP for public television depends on probable usage, the consumer's budget, and choice-preference measures, whether stated explicitly (Thayer 1981) or implicitly (Edwards and Anderson 1987). With the spread of gambling and the advent of "look-alike" cable television channels, however, consumers have alternatives. A reduced-form model of WTP identifying new available substitute opportunities is as follows:

$$
\begin{gathered}
\mathrm{WTP}=\mathrm{f}(\text { View }, \text { Income, Education, Age, Children, Gambling Budget, } \\
\text { Frequency of Casino Visits, Fondess for Gambling })
\end{gathered}
$$

The dependent variable, WTP, was derived from the question: What is the most you (your household) would be willing to pay each year to maintain public television in Las Vegas? We expect that WTP for public television will be influenced by three gaming variables. The first is the amount of money budgeted for gambling, as measured by the variable Gambling Budget = dollars budgeted for gambling per week. Individuals who budget large amounts of money for gambling at casinos should, other things equal, have less discretionary money for contributing to PBS. Second, the frequency with which a person visits a casino may influence WTP. We measure casino frequency with categorical dummy variables: Infrequent or Never (the omitted reference group), Visit Casino Frequently (at least once a week), and Visit Casino Monthly (about once a month). The third variable is Gambling Fondness, which is measured with one dummy variable: $1=$ strongly agree/agree and $0=$ strongly disagree/disagree or neutral with the statement "I like to gamble." We test for the significance of the gambling budget, the frequency of casino visits, and fondness for gambling variables separately.

Likewise, those who view more public television are more likely to contribute to public television, as demonstrated by Kingma and McClelland's study (1995). View is measured by three indicator variables reflecting categories of viewing public television: none (the omitted reference group), less then 5 hours per week (View 2), and 5 hours or more per week viewing public television (View 3).

Viewers of public television, at least as reflected in the rhetorical criticisms of some, are seen as highbrow, intellectual, and elitist. As such, respondents with a college education should be more likely contributors than individuals with less education. The model includes a dummy variable equal to one if the respondent has a college education, zero otherwise.

Considering the quality of PBS educational programming for children, such as the highly acclaimed "Sesame Street," households with children seeking to ensure quality programming for their children might contribute more to PBS, other things equal. On the other hand, the presence of children may limit a household's discretionary spending. As such, the expected sign of the variable Children 
( 1 = if child in the household; 0 otherwise) remains uncertain, depending on the relative contributions of these juxtaposed factors.

Income and age were not significant variables in earlier studies. Yet, intuitively, one might expect these variables to influence WTP. Larger income households, having more discretionary income, may be more likely to contribute to public television than smaller income households. We test for the income influence with three dummy variables: Income $1=$ less than $\$ 25,000$ (the reference group), Income $2=\$ 25,000-\$ 49,999$, and Income $3=\$ 50,000$ and more.

Older viewers who are more likely to be retired (living on a fixed income) and younger adults (not having reached their peak income earning years) may not have the discretionary income that would allow them to contribute to public television as they would otherwise. Therefore, it is expected that individuals aged 35 to 54 will be the most likely to contribute. Three binary variables, each equal to one if the individual is between 18 and 34 years of age (the omitted reference group), 35-54 years of age (Age 2), and 55 or more years of age (Age 3), zero otherwise, are included.

\section{EMPIRICAL RESULTS}

The data for this study, obtained from a large survey (Las Vegas Perspective) on the lifestyles of Las Vegans, included questions related to public television contributions and gambling behavior. ${ }^{1}$ Two questions assessed public television viewing behavior. The first asked how many hours a week respondents watched PBS, with the possible response categories being never, less than 5 hours, 5-9 hours, 10-14 hours, 15-19 hours, and 20 or more hours. The second asked the respondents (or their household) the most they would be willing to pay each year to maintain PBS in Las Vegas. In addition, other questions asked the average amount of money personally budgeted on gaming per week; frequency of casino visitation; attitude toward gambling; and their demographic characteristics, such as income, education, and age.

The survey used a mail format with two follow-up reminders. During October and November of 1994, 4,927 questionnaires were mailed to a simple random sample of households; 1,054 were returned for a 21.4 percent return rate. Eight hundred eighty cases provided completed information on all the variables in two of the analyses, 557 cases in the third analysis. Table 1 shows definitions and descriptions of all variables along with sample means and standard deviations for each variable. As expected, the order statistics for WTP revealed that slightly more than half of the survey respondents were unwilling to contribute to PBS, suggestive of a limited range for the dependent variable.

\footnotetext{
${ }^{1}$ The Center for Business and Economic Research has conducted an annual survey, the Las Vegas Perspective, since 1981. Questionnaire and survey design follow Dillman's (1978) approach. In 1994, a 13-page booklet was used covering a broad range of topics including public television; shopping activities; community concerns; job search; gaming activities; recycling practices; spending, saving, and handling of money; and participation in physical activities. In addition, demographic questions were asked. As such, the questions on WTP for public television and on gaming were part of a larger survey.

The survey was stratified by zip code area. Sample sizes for each zip code area with oversampling for areas with historically lower-than-average response rates. A commercial vendor provided a sample of randomly selected households.
} 
TABLE 1

Description of Variables and Descriptive Statistics

\begin{tabular}{|c|c|c|c|c|c|}
\hline \multirow[b]{2}{*}{ Variable } & \multirow[b]{2}{*}{ Description } & \multicolumn{2}{|c|}{$\begin{array}{l}\text { Models Using } \\
\text { Gambling Budget }\end{array}$} & \multicolumn{2}{|c|}{$\begin{array}{c}\text { Model Using } \\
\text { Casino Visitation } \\
\text { Fondness for Gambling }\end{array}$} \\
\hline & & $\mathrm{M}$ or $\%$ & SD & $\mathrm{M}$ or $\%$ & SD \\
\hline $\begin{array}{l}\text { Dependent Variable } \\
\text { Independent Variables: }\end{array}$ & $\begin{array}{l}\text { Amount WTP for } \\
\text { public television }\end{array}$ & $\$ 18.98$ & 41.85 & $\$ 20.42$ & 43.68 \\
\hline $\begin{array}{l}\text { Gambling Budget } \\
\text { (in dollars) } \\
\text { Visit Casino Frequently }\end{array}$ & $\begin{array}{l}\text { Amount budgeted for } \\
\text { gaming per week } \\
1=\text { if visit casino at } \\
\text { least once a week }\end{array}$ & $\$ 36.82$ & 86.72 & 0.39 & 0.49 \\
\hline Visit Casino Monthly & $\begin{array}{l}1=\text { if visit casino } \\
\text { about once a month }\end{array}$ & & & 0.24 & 0.43 \\
\hline Gambling Fondness & $\begin{array}{l}1=\text { if strongly agree/agree } \\
\text { with "I like to gamble." }\end{array}$ & & & 0.29 & 0.45 \\
\hline View 2 & $\begin{array}{l}1=\text { if view public } \\
\text { television less than } \\
5 \text { hours per week }\end{array}$ & 0.54 & 0.50 & 0.54 & 0.50 \\
\hline View 3 & $\begin{array}{l}1=\text { if view public } \\
\text { television } 5 \text { hours or } \\
\text { more per week }\end{array}$ & 0.29 & 0.45 & 0.29 & 0.45 \\
\hline College & $1=$ if completed college & 0.42 & 0.49 & 0.42 & 0.49 \\
\hline Children & $\begin{array}{l}1=\text { if presence of } \\
\text { children in household }\end{array}$ & 0.23 & 0.42 & 0.28 & 0.45 \\
\hline Age 2 & $1=$ if $35-54$ years of age & 0.41 & 0.49 & 0.43 & 0.50 \\
\hline Age 3 & $\begin{array}{l}1=\text { if } 55 \text { or more } \\
\text { years of age }\end{array}$ & 0.38 & 0.49 & 0.35 & 0.48 \\
\hline Income 2 & $1=$ if $\$ 35,000-\$ 49,999$ & 0.36 & 0.48 & 0.36 & 0.48 \\
\hline Income 3 & $1=$ if $\$ 50,000$ and more & 0.42 & 0.49 & 0.44 & 0.50 \\
\hline Number of Cases & & & & & \\
\hline
\end{tabular}

On average, respondents were willing to contribute $\$ 20.42$ to maintain PBS programming locally (zeroes included). To be sure, the percentage of households willing to contribute and the amount they are WTP to keep PBS (an all-or-nothing question) are expected to be greater than the percentage of households currently contributing and the amount they contribute. The amount they budgeted for gaming per week was higher, at $\$ 36.82$. Fifty-two percent watched public television less than 5 hours per week, another 30 percent watched 5 hours or more a week, and 18 percent never watched PBS.

The presence of a large percentage of households unwilling to contribute to PBS (52.8 percent of the respondents) resulted in censoring at the lower tail of the distribution of WTP responses, reason for concern in this case about the appropriateness of Ordinary Least Squares (OLS) assumptions to the data. In particular, a large proportion of the dependent variable equaling zero tends to bias parameters toward zero (Greene 1990, p. 730). Thus, we estimated WTP formulations using the Tobit estimation procedure. ${ }^{2}$

\footnotetext{
${ }^{2}$ As anticipated, the absolute values of coefficients for the Tobit equations exceeded those of the OLS equations.
} As such, only the Tobit results are presented. Results from OLS are available upon request. 


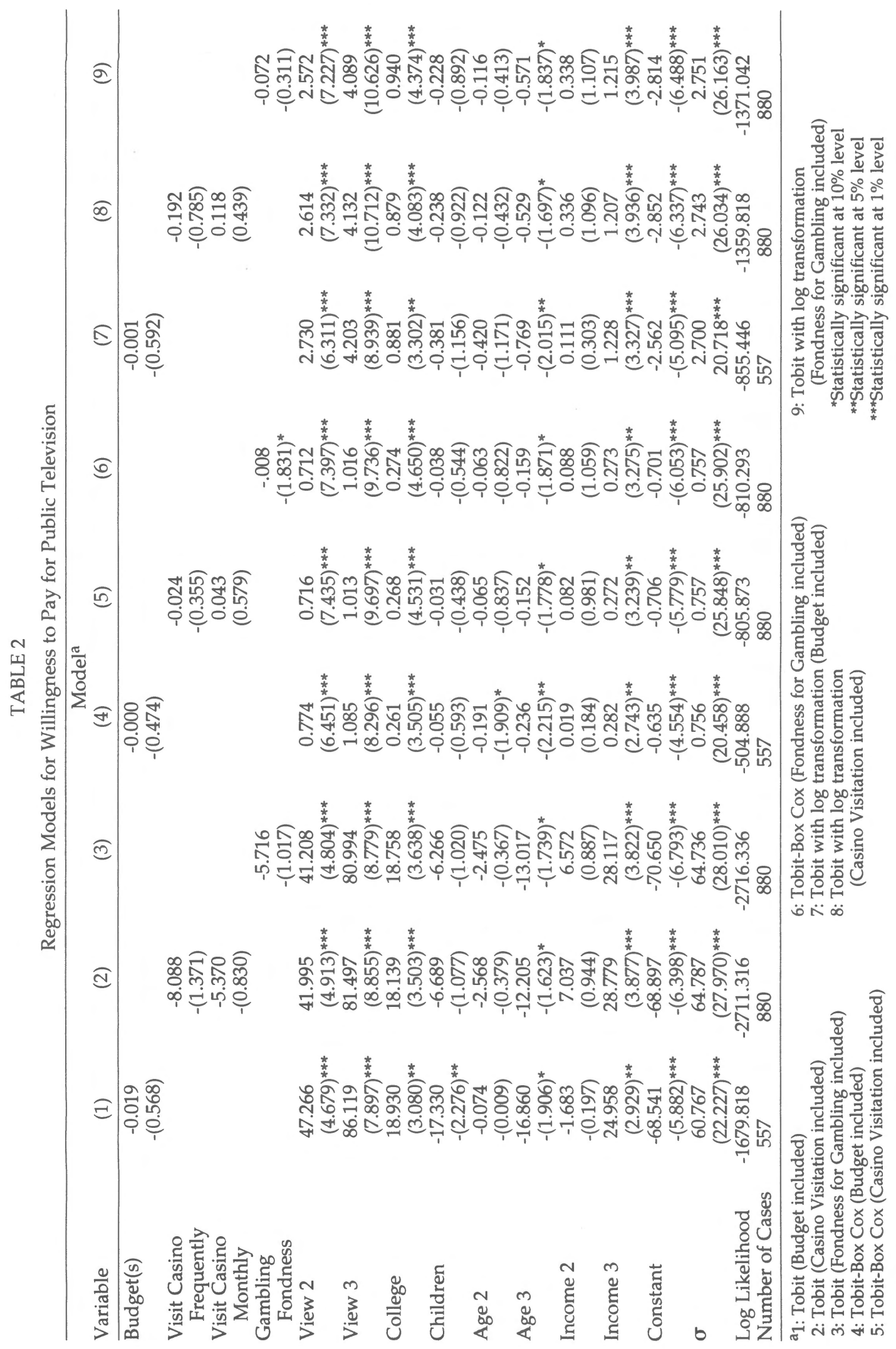


Three regression models, each one using a gaming variable, were estimated (see Table 2). Indeed, the use of all three gaming variables resulted in multicollinearity. As a result, we did not consider the three variables simultaneously, preferring to compute models with each variable separately. Model 1 used the gambling-budget measure, Model 2 the two frequency of casino visitation variables, and Model 3 the fondness for gambling variable. The other explanatory variables were the same for these three models.

Consistent with Schwer and Daneshvary (1995), a college education and amount of viewing time of PBS were important predictors of WTP. Viewing time significantly increased WTP for public television. This finding is also consistent with those of Kingma and McClelland (1995). The coefficient of the College variable had the expected sign and was significant at the $1 \%$ level for two models. Individuals with a college education were likely contributors to public television, which lends some credence to the highbrow, elitist, and intellectual stereotype of PBS viewers. We find statistically significant coefficients for Models 1 through 3.

The coefficients on Age 2 and Age 3 imply a negative relationship between increased age and WTP for public television in all three models. The coefficient on Age 3 in all three models was significant at the $10 \%$ level, implying that younger respondents were more receptive to PBS giving than older respondents. The lifecycle hypothesis suggests that discretionary spending would be greater for individuals 35-54 years of age than for older persons. We find this to be the case for giving to public television.

As hypothesized, higher income households $(\$ 50,000$ and more) were more likely to contribute to public television than lower income households. The coefficients for this variable were positive and significant for all three models.

Amount budgeted for gambling in all the models did not significantly influence WTP; however, it had the expected negative sign. As such, the evidence suggests that gaming does not significantly shift consumer spending, that is, money is not diverted from nongaming activities to gaming activities. The exclusion of gaming expenditures from Models 2 and 3 precluded a direct assessment of the dollar impact on WTP; however, frequency of casino visitation, as measured by two categorical variables, and fondness for gambling, as measured by one variable, were inversely related to WTP, but not significant.

The expected sign of the variable Children was negative in Model 1, suggesting that contributions for the continuance of quality children's programming is constrained by other household expenditures.

Using the Davidson and MacKinnon (1981) test for nonlinearity for models using three separate gaming formulations (gambling budget, frequency of casino visits, and fondness for gambling), we concluded that a log-linear formulation added significantly to the linear fit, supporting the use of a nonlinear model. However, rather than specify a given nonlinear functional form, we first used a standard Tobit model with a Box-Cox transformation similar to that used in previous research on charitable giving (Lankford and Wyckoff 1991). Results for the Box-Cox formulation for nonlinearity with a Tobit framework are shown as 
models 4, 5, and 6 in Table 2. Models 7, 8, and 9 present results for the popular log transformation.

The maximum likelihood estimate of $\lambda$, the power transformation of the dependent variable, yielded best fits for a value of 0.0236 with a $95 \%$ confidence interval of -0.0866 and 0.0499 . The estimate reflects the presence of significant nonnormality of the WTP variable. Nonpositive values of WTP were automatically restricted to be untransformed. We tested for significant differences between hypothesized values of $-1,0$, and 1 and the estimated $\lambda$ using a likelihood ratio test with resulting chi-square coefficients of $910.98,0.27$, and 830.56 . Only in the case of $\lambda=0$ did we find a statistically insignificant difference with the estimated $\lambda$. As a result, the Box-Cox transform is not significantly different from the transform of ln WTP.

All coefficients in the three formulations of Tobit equations (standard, BoxCox transform and log transform) had the expected signs. Moreover, statistically significant coefficients for all models were found for the length of time spent viewing PBS, level of education, and income (variables identified as View 2, View 3 , College, and Income 3). In only one case did we find a significant coefficient for a gaming variable, children, and age (the Gambling Fondness, Children, and Age 2 variables). Thus, gaming behavior is at best weakly associated with giving to public television, as measured by the sign and statistical significance of the estimated coefficients.

The partial derivatives reveal estimates of the expected changes in the value of WTP with respect to the mean values of the independent variables rather than the impact of a change in the independent variables, holding the other explanatory variables constant, on the log odd of WTP. The weakness of the significant Gaming Fondness variable in Model 6 becomes more apparent from the partial derivatives shown in Table 3. All else being equal, a fondness for gambling as measured by responses to an attitudinal question (strongly agree/agree) contributes very little adverse effect to willingness to contribute $(-0.005)$. Thus, we find the gambling effect is minimal in the only case in which gambling behavior yielded a statistically significant coefficient.

\section{DISCUSSION}

Our results indicate that charitable contributions to public television depend primarily on demographic and economic conditions, but not on gambling activity. Only one of the three gambling behavior variables has a statistically significant impact (and in this case the effect is decidedly weak), and the Box-Cox Tobit formulation proved the better functional form (though the estimated $\lambda$ is not significantly different from zero). The findings derived from a standard Tobit fit, a Tobit with a Box Cox transform, and a Tobit of a log transform are consistent, however, with earlier studies showing that time spent viewing public television is perhaps the best indicator of giving to PBS. Using Tobit models (to account for the significant number of zeroes reflecting the respondents who were unwilling to 


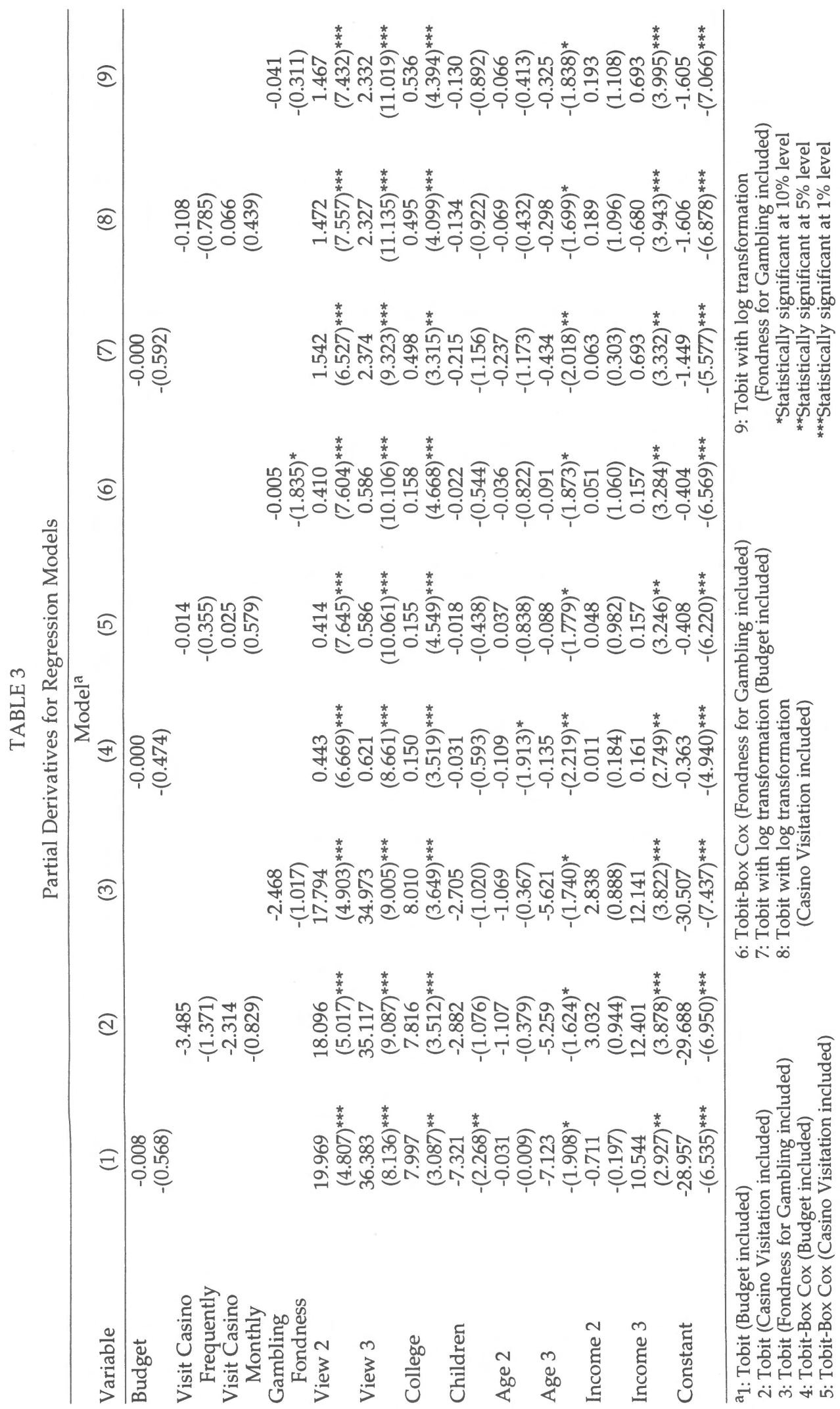


contribute to PBS) and transformations (to account for nonlinearities), we show that the coefficients on level of education, age, and income are also statistically significant and had the expected signs. Nonsenior-age respondents, with a higher level of education and income, are the most likely contributors to PBS. One's attitude toward gambling, measured as fondness for gambling, is significantly related to charitable giving (however, only in the case of the Box-Cox transformation), whereas frequency of casino visitation and amount of gambling budget, in all cases, are not. Lastly, the Tobit with a Box-Cox transformation is not significantly different from a Tobit with a log transform of the dependent variable.

Casino gambling's socioeconomic impact on society, to be sure, is measurable and significant as indicated by previous research. Yet, the larger significance of our findings suggests that gambling behavior, as defined in this study, does not significantly affect contributions to PBS when studied in an environment where the transitory effects of recent gambling legalization are not present.

Based on our findings, one cannot, however, generalize the effect that gambling activity will have on giving to other charitable organizations. Indeed, respondents who contribute to PBS may be motivated by nonaltruistic reasonsthey may perceive a direct benefit from giving by receiving quality television programming. Moreover, a body of literature on charitable giving suggests that people are more likely to give to organizations when they perceive a direct benefit. Of interest would be research that addresses casino gambling's impact on residents' giving to other charitable organizations, such as the Red Cross or United Way, for households located in regions experiencing both transitory periods of recent gambling legislation and more stable gaming environments.

\section{REFERENCES}

Aasved, M. J., and J. C. Laundergan. "Gambling and Its Impacts in a Northeastern Minnesota Community: An Exploratory Study." Journal of Gambling Studies 9 (1993), 301-319.

Aasved, M. J., J. M. Schaefer, and K. Merila. "Legalized Gambling and Its Impacts in a Central Minnesota Vacation Community: A Case Study." Journal of Gambling Studies 11 (1995), 137-163.

Bohm, P. "Estimating Demand for Public Goods: An Experiment." European Economic Review 3 (1972), 111-130.

Boot, M. "Competing with Big Bird." The Wall Street Journal, 23 October 1995, sec. A, p.18, col. 3.

Borg, M. O., P. M. Mason, and S. L. Shapiro. The Economic Consequences of State Lotteries. New York: Praeger, 1991.

Brookshire, D. S., M. A. Thayer, W. D. Schulze, and R. C. d'Arge. "Valuing Public Goods: A Comparison of Survey and Hedonic Approaches." The American Economic Review 72 (1982), 165-177.

Buck, A. J., J. Deutsch, S. Hakim, U. Spiegel, and J. Weinblatt. "A Von Thünen Model of Crime, Casinos and Property Values in New Jersey." Urban Studies 28 (1991), 673-686. 
Davidson, R., and J. MacKinnon. "Several Tests for Model Specification in the Presence of Multiple Alternatives." Econometrica 49 (1981), 781-793.

Desvousges, W. H., V. K. Smith, and M. P. McGivney. A Comparison of Alternative Approaches for Estimating Recreation and Related Benefits of Water Quality Improvements. Report No. EPA-230/05-83-001, Washington, D.C.: Office of Policy Analysis, U.S.Environmental Protection Agency, 1983.

Dillman, D. A. Mail and Telephone Surveys. New York: John Wiley \& Sons, 1978.

Edwards, S. F., and G. D. Anderson. "Overlooked Biases in Contingent Valuation Surveys: Some Considerations." Land Economics 63 (1987), 168-178.

Friedman, J., S. Hakim, and J. Weinblatt. "Casino Gambling as a 'Growth Pole' Strategy and Its Effect on Crime." Journal of Regional Science 29 (1989), 615-623. Gaudia, R. "Effects of Compulsive Gambling on the Family." Social Work 42 (1987), 254-256.

Gazel, R., D. Rickman, and W. N. Thompson. "Economic Impacts of Casino Gambling: The Case of Wisconsin." Paper presented at the Society for Applied Sociology, 1995.

Giannini, B., T. Carroll, M. Clauretie, N. Daneshvary, and H. Neill. "Residential Property Values and Casinos in Henderson, Nevada: A Hedonic Price Model." Manuscript submitted for publication, 1997.

Goetze, L., T. F. Glover, and B. Biswas. "The Effects of Group Size and Income on Contributions to the Corporation for Public Broadcasting." Public Choice 77 (1993), 407-414.

Greene, W. H. Econometric Analysis. New York: Macmillian Publishing Company, 1990.

Kingma, B. R., and R. McClelland. "Public Radio Stations Are Really, Really Not Public Goods: Charitable Contributions and Impure Altruism." Annals of Public and Cooperative Economics 66 (1995), 65-76.

Lankford, R. H., and J. H. Wyckoff. "Modeling Charitable Giving Using a Box-Cox Standard Tobit Model." The Review of Economics and Statistics 73 (1991), 460-470. Loehman, E. T., D. Boldt, and K. Chaikin. "Measuring the Benefits of Air Quality Improvements in the San Francisco Bay Area." Final report to the U.S. Environmental Protection Agency, SRI International, Menlo Park, CA, 1981.

Madden, M. K. "Economic and Fiscal Impacts Associated with Gaming Deadwood, South Dakota." University of South Dakota, South Dakota Commission on Gaming, 1992.

Ruple, B. "Everybody Loves Big Bird." The Wall Street Journal, 7 November 1995, sec. A, p. 23, col. 1.

Schwer, R. K., and R. Daneshvary. "Willingness to Pay for Public Television and the Advent of 'Look-Alike' Cable Television Channels: A Case Study." The Journal of Media Economics 8 (1995), 95-109.

Sinden, J. A. "Empirical Tests of Hypothetical Biases in Consumers' Surplus Surveys." Australian Journal of Agricultural Economics 32 (1988), 98-112. 
Thayer, M. "Contingent Valuation Techniques for Assessing Environmental Impacts: Further Evidence." Journal of Environmental Economics and Management 8 (1981), 27-44.

Vining, A. R., D. Weimer, A. E. Boardman, and D. Greenberg. The Use of Contingent Valuation to Value Environmental Impacts. Unpublished manuscript, Simon Fraser University, Burnaby, British Columbia, Canada, 1994. 
